\title{
BMJ Open Recorded gonorrhoea rates in Denmark, 1900-2010: the impact of clinical testing activity and laboratory diagnostic procedures
}

\author{
Inga Lind, Steen Hoffmann
}

To cite: Lind I, Hoffmann S. Recorded gonorrhoea rates in Denmark, 1900-2010: the impact of clinical testing activity and laboratory diagnostic procedures. BMJ Open 2015;5:e008013. doi:10.1136/bmjopen-2015008013

- Prepublication history for this paper is available online. To view these files please visit the journal online (http://dx.doi.org/10.1136/ bmjopen-2015-008013).

Received 4 March 2015 Revised 30 October 2015 Accepted 2 November 2015

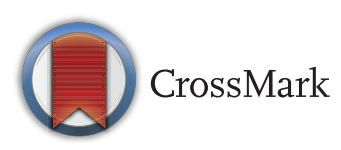

Department of Microbiology and Infection Control, Statens Serum Institut, Copenhagen S, Denmark

Correspondence to Dr Steen Hoffmann; hof@ssi.dk

\section{ABSTRACT}

Objectives: Assessment of the relations between recorded gonorrhoea rates and clinical testing activity and disposable diagnostic tests.

Methods: In Denmark, two sources of information on the epidemiology of gonorrhoea are available: (1) a mandatory clinical notification system (since 1867) comprising summary information about geographic distribution, season, age group and gender; in 1994, more detailed anonymous individualised epidemiological information was included; (2) a voluntary countrywide laboratory surveillance system for culture-confirmed cases (since 1957) comprising information about patient's age and gender, infected anatomical sites and medical setting attended.

Results: Both surveillance systems showed marked simultaneous changes in gonorrhoea rates, although periodically considerable under-reporting or under-diagnosing was demonstrated. The annual incidence of notified cases peaked in 1919 (474/ 100 000), in 1944 (583/100 000) and in 1972 (344/ $100000)$. Since 1995 , the incidence has been at a low endemic level (1.5-10/100 000) and the total male/ female incidence ratios were from 3 to 7 times higher than previously recorded. Among approximately 2 million persons tested during 1974-1988 78213 men and 63143 women with culture-confirmed gonorrhoea were identified. During this period, pharyngeal sampling was performed in $36 \%$ of men and $25 \%$ of women with gonorrhoea; pharyngeal gonorrhoea was found in $10 \%$ and $16 \%$, respectively; $40 \%$ and $30 \%$ of these patients had no concomitant urogenital gonorrhoea. Among men with gonorrhoea, $34 \%$ were sampled from the rectum; $9 \%$ had rectal gonorrhoea, among whom the rectum was the only infected site in $67 \%$.

Conclusions: Crucial factors for case finding are clinical sampling tradition and appropriate laboratory diagnostic facilities. When case finding is insufficient, a reservoir of asymptomatic rectal or pharyngeal gonorrhoea remains unrecognised.

\section{INTRODUCTION}

In Denmark, information on the epidemiology of gonorrhoea is based on a clinical

\section{Strengths and limitations of this study}

- We are in the unusual situation where the assessment of the occurrence of gonorrhoea in Denmark can be based on two continuous nationwide surveillance systems: a mandatory clinical notification system (since 1867) and a voluntary laboratory surveillance system (since 1957). Before the mid-1960s, the majority of notified cases were among men and the majority of laboratory-confirmed cases among women. Since then, culture has also been widely used for the diagnosis of gonorrhoea in men. During the past $40-50$ years, both surveillance systems showed marked simultaneous changes in gonorrhoea rates.

- Between 1974 and 1988, the strength of the data was at a maximum due to the following facts: a case definition was laid down in the Venereal Disease Act 1973, the prevalence of disease was high, the testing activity was high and diagnostic facilities and treatment were available for all medical settings free of charge.

- The study limitations are due to (1) the lack of information of testing practice for patients without laboratory-confirmed gonorrhoea, that is, the proportion of lost cases is unknown, (2) the fact that both systems are anonymous, that is, we can only estimate the degree of underreporting or underdiagnosing of cases and (3) possible changes in sexual behaviour cannot be inferred from our data.

notification system (since 1867) and a countrywide laboratory surveillance system (since 1957). The public health strategies for the prevention of sexually transmitted diseases (STDs) comprise legislation, health educational programmes and regulations governing control of infectious diseases in general. Legislation specifically dealing with STDs goes back to 1773 , including the patients' right to receive free treatment, and was laid down in the 'Act on Measures to Combat the Spread of Venereal Infections' in 1874. 
In 1877, uniform notification forms for selected communicable diseases including syphilis, gonorrhoea and ulcus venereum (ulcus molle) were introduced. In 1906, a total revision resulted in 'The Act Regarding the Combating of Public Immorality and Venereal Infection'. This Act prohibited prostitution, abolished all control systems regarding prostitutes and enabled penal measures to be undertaken against those patients who did not fulfil their duty to comply with examination, treatment and to report the identity of their sexual contacts. The most important step to prevent further spread of the diseases was the continued provision of free treatment at public STD clinics. The next major amendment was in 1947, which, owing to the recent epidemic during World War II (WW2), implied an intensification of rules for contact tracing and duty to receive treatment. The revised law of 1973 stressed an increased personal responsibility for prevention and control of STDs. This trend continued and resulted in the abolition of legislation specifically concerning STDs in 1988. After the abolition of the Venereal Disease Act, the National Board of Health (NBH) still has obligations to supply official guidelines for prevention, diagnosis and treatment of STDs. ${ }^{2}$ However, the annulment implied that treatment was no longer free of charge except at the few public STD clinics maintained after the decentralisation of public expenses in 1980. The change in legislation released local authorities from the obligation to organise facilities for medical care and contact tracing.

The main objective of this paper is to discuss the importance of sampling from multiple sites and of the availability of appropriate laboratory diagnostic tests for case finding.

\section{METHODS}

\section{Clinical notification system}

The system is obligatory and comprises the following STDs (year of first annual report): gonorrhoea (1877), early syphilis (1877) and AIDS (1983); ulcus molle (1877) and lymphogranuloma venereum (1938) were omitted from the notification system from 1994 and onwards. ${ }^{1}$ Initially, the diagnosis of gonorrhoea was based on symptoms, signs and patient history; after 1884, the diagnosis might be supported by microscopy of Gram-stained smears ${ }^{3}$ of urogenital secretions; in 1940, facilities for culture of Neisseria gonorrhoeae became available at Statens Serum Institut (SSI). A case definition was for the first time laid down in the Venereal Disease Act in 1973: $N$. gonorrhoeae should be demonstrated by microscopy or culture. This implied that standardised laboratory diagnostic services should be available free of charge at SSI for all STD clinics, medical officers (MOs) and authorised general practitioners (GPs).

The obligatory records ('weekly lists') were numerical and anonymous showing distribution according to region, season, age group (15-64 years not subdivided) and gender. The NBH was responsible for annual surveys based on these data. From 1980, the Department of Epidemiology at SSI was responsible for the handling of all data. The most recent revision in 1994 required that notifications included information about diagnostic procedures used, age and gender of individual patients, assumed country of exposure to infection, HIV status, known presence of other STDs and sexual orientation, but no case definition was included.

\section{Laboratory surveillance system}

After periods with sentinel assessment of the prevalence of culture-confirmed gonorrhoea cases, a permanent laboratory surveillance system was established at the Neisseria Department, SSI, in 1957. ${ }^{4}$ After the mid-1960s, laboratory services were gradually decentralised (see below), but the reporting system was maintained through a close, voluntary collaboration between SSI and the local departments of clinical microbiology (DCMs). Culture-confirmed diagnosis of gonorrhoea was provided solely by public laboratories. The reports comprised information about patient's age and gender, infected anatomical sites and medical setting attended. Specific registration of cases of pharyngeal gonorrhoea was included in 1973 and that of rectal gonorrhoea in men in 1981. Since 1994 when mandatory, individual, anonymous laboratory reporting of confirmed cases was included in the law on measures against selected infectious diseases, a central registration of culture-confirmed cases based on isolates received at SSI was maintained. Information about patients who tested negative was not included.

\section{Laboratory diagnosis}

Microscopy of genital secretions after Gram staining was performed at the STD clinics on the day of attendance. The laboratory procedures for culture of gonococci at SSI developed since $1940^{5-7}$ were based on the comprehensive studies performed earlier by Reymann. ${ }^{8}$ Table 1 shows changes in antimicrobial supplements used in media for primary isolation of gonococci. Local DCMs used the same media produced at SSI. Since 2007, nucleic acid amplification tests (NAATs) have been used as a diagnostic supplement. At major STD clinics in Copenhagen, sampling from the rectum became a routine procedure in both genders around $1950^{9}$; the importance of bacteriological diagnosis of pharyngeal infection was not addressed before $1972 .{ }^{10}$ Subsequently, all STD clinics routinely included taking of pharyngeal specimens from all patients.

\section{RESULTS}

\section{Clinical notification system}

Figure 1 shows the annual incidence of gonorrhoea based on the number of cases notified to the NBH since the year 1900; the years of major amendments on legislation $(1906,1947,1973,1988)$ and changes of the clinical 


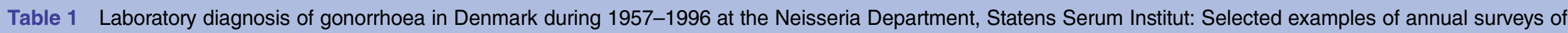
culture-confirmed cases and testing activity

\begin{tabular}{|c|c|c|c|c|c|c|c|c|c|c|c|c|c|}
\hline \multirow[b]{3}{*}{ Period } & \multirow{3}{*}{$\begin{array}{l}\text { Antimicrobials added to media for } \\
\text { primary isolation of Neisseria } \\
\text { gonorrhoeae* }\end{array}$} & \multirow[b]{3}{*}{ Year } & \multicolumn{3}{|c|}{$\begin{array}{l}\text { Number of } \\
\text { culture-confirmed } \\
\text { cases }\end{array}$} & \multicolumn{8}{|c|}{ Testing activity } \\
\hline & & & \multirow[b]{2}{*}{ Men } & \multirow[b]{2}{*}{ Women } & \multirow[b]{2}{*}{ Total } & \multicolumn{3}{|c|}{$\begin{array}{l}\text { Number of specimens } \\
\text { tested }\end{array}$} & \multicolumn{3}{|c|}{$\begin{array}{l}\text { Percentage positive } \\
\text { specimens }\end{array}$} & \multicolumn{2}{|c|}{$\begin{array}{l}\text { Average } \\
\text { number of } \\
\text { sampling } \\
\text { sites per } \\
\text { caset }\end{array}$} \\
\hline & & & & & & Men & Women & Total & Men & Women & Total & Men & Women \\
\hline \multirow[t]{2}{*}{ 1957-1959 } & None & 1957 & 1684 & 2299 & 3983 & 15435 & 60983 & 76418 & 12.9 & 8.3 & 9.2 & $N A \ddagger$ & NA \\
\hline & & 1959 & 2193 & 2934 & 5127 & 18352 & 70361 & 88713 & 15.4 & 8.5 & 9.9 & NA & NA \\
\hline \multirow[t]{2}{*}{$1960-1964$} & Polymyxin B sulfate, nystatin or both & 1960 & 2835 & 3581 & 6416 & 20972 & 81491 & 102463 & 16.8 & 9.5 & 11.0 & NA & NA \\
\hline & & 1964 & 2936 & 2934 & 5870 & 23491 & 86482 & 109976 & NA & NA & 8.8 & NA & NA \\
\hline \multirow[t]{4}{*}{ 1965-1973 } & Ristocetin added to the above & 1965 & 3112 & 3027 & 6139 & 25465 & 91660 & 117125 & NA & NA & 8.8 & NA & NA \\
\hline & 1965-1968, and then replaced with vancomycin & 1968 & 5918 & 5675 & 11593 & 45867 & 115942 & 161809 & 13.2 & 9.1 & 9.7 & 1.2 & 2.1 \\
\hline & & 1972 & 9054 & 8349 & 17403 & 79362 & 224256 & 314311 & 11.5 & 6.4 & 7.2 & 1.2 & 2.1 \\
\hline & & 1973 & 8731 & 7444 & 16175 & 81974 & 218037 & 311946 & 10.7 & 5.8 & 6.7 & 1.2 & 2.2 \\
\hline \multirow[t]{2}{*}{$1974-1979 \S$} & 1) Polymyxin B sulfate, nystatin, & 1974 & 7934 & 6726 & 14660 & 82519 & 236845 & 323211 & 10.9 & 4.7 & 5.8 & 1.5 & 2.2 \\
\hline & vancomycin 2) trimethoprim lactate & 1979 & 5790 & 4884 & 10674 & 79502 & 240773 & 320275 & 7.5 & 3.2 & 4.2 & 1.6 & 2.1 \\
\hline \multirow[t]{5}{*}{ 1980-1996 } & Amphotericin B, lincomycin, & 1980 & 6043 & 4798 & 10841 & 78289 & 225717 & 304006 & 8.0 & 3.4 & 4.6 & 1.6 & 2.1 \\
\hline & polymyxin B sulfate, trimethoprim lactate & 1983 & 5545 & 4418 & 9963 & 85217 & 187644 & 272861 & 6.8 & 3.8 & 4.7 & 1.8 & 2.0 \\
\hline & & 1988 & 1362 & 1136 & 2498 & 38174 & 87944 & 126198 & 3.6 & 1.9 & 2.4 & 1.7 & 1.9 \\
\hline & & 1995 & 50 & 12 & 62 & 3778 & 9137 & 12915 & 1.3 & 0.14 & 0.48 & 1.4 & 1.5 \\
\hline & & 1996 & 25 & 13 & 38 & 2481 & 7143 & 9624 & 1.0 & 0.21 & 0.39 & 1.1 & 1.3 \\
\hline
\end{tabular}

${ }^{*}$ Concentrations of antimicrobials used in selective media: polymyxin B sulfate $25 \mathrm{U} / \mathrm{mL}$; nystatin $25 \mathrm{U} / \mathrm{mL}$; ristocetin $10 \mu \mathrm{g} / \mathrm{mL}$; vancomycin $2 \mu \mathrm{g} / \mathrm{mL}$; amphotericin B $2 \mu \mathrm{g} / \mathrm{mL}$; lincomycin $1 \mu \mathrm{g} / \mathrm{mL}$; trimethoprim lactate $3 \mu \mathrm{g} / \mathrm{mL}$.

tPossible sampling sites included urethra (cervix), rectum and pharynx.

NA=data not available.

§All specimens inoculated onto both media. 
Figure 1 Annual incidence (cases per 100000 population) of gonorrhoea and early syphilis during 1901-2010 and of AIDS during 1981-2010 reported to the National Board of Health. Years of major amendments on legislation: 1906 The Act regarding the combating of public immorality and venereal infections; 1947 and 1973 Amendments of The Venereal Disease Act; 1980 and 1994 Revision of the notification system for communicable diseases; 1988 Abolition of The Venereal Disease Act.

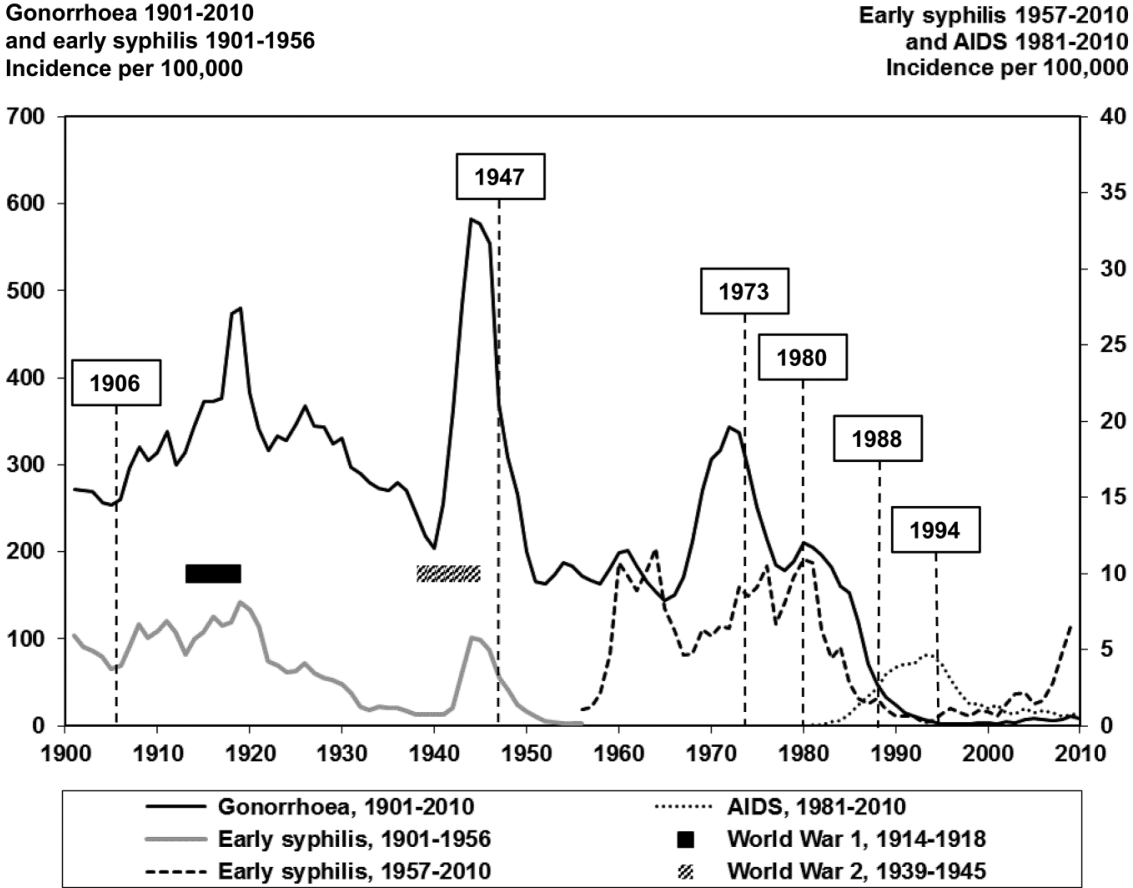

notification system $(1980,1994)$ are indicated. The changes in gonorrhoea rates observed were not closely related to these legislative approaches. For comparison, changes in the incidences of early syphilis and AIDS are included. The gonorrhoea and syphilis curves are fairly congruent apart from the 1970s when only gonorrhoea rates were increased. The occurrence of AIDS reached peak figures in the 1990s.

During WW1, a gonorrhoea epidemic peaking in 1919 with an incidence of 474/100000 occurred; subsequently, the gonorrhoea incidence fell to the lowest ever recorded at that time. Another epidemic occurred during WW2 (1944: 583/100 000). However, after the war, the steady decrease in prevalence continued until the mid-1960s except for a small peak around 19621963 due to an outbreak concurrent with an epidemic of syphilis among homosexual men. ${ }^{11}$ Then a marked increase peaking in $1972(344 / 100000)$ was seen. Within the following 20 years, the decrease was dramatic except for a slight increase in the beginning of the 1980s, again due to an outbreak among homosexual men (figure 1) ${ }^{12}$ (1982:39; 1987:49).

Since the beginning of the 1990 s, the gonorrhoea rate has been at a low endemic level $(<10 / 100000)$, attaining a minimum in 1996 (1.5/100 000). Subsequently, minor clusters occurred among men during 1999-2000 and 2004-2006 and another among both genders during $2009^{12}$ (2010:36). Data available for the period 19942010 showed that the majority of gonorrhoea cases were among men: on the average, $45 \%$ (range 27-61\%) had acquired the infection by homosexual contact and $29 \%$ (range 14-39\%) had acquired the infection abroad;

Table 2 Incidence of culture-confirmed gonorrhoea per 100000 population and male/female incidence ratios for the age groups 15-19, 20-24, 25-29 years and total

\begin{tabular}{|c|c|c|c|c|c|c|}
\hline \multirow[b]{2}{*}{ Year } & \multirow[b]{2}{*}{ Population (thousands) } & \multirow[b]{2}{*}{ Incidence per 100000} & \multicolumn{4}{|c|}{ Male/female incidence ratios } \\
\hline & & & 15-19 years & 20-24 years & $25-29$ years & Total \\
\hline 1960 & 4566 & 140.5 & 0.29 & 0.94 & 1.29 & 0.80 \\
\hline 1965 & 4741 & 129.5 & 0.34 & 1.07 & 1.89 & 1.05 \\
\hline 1970 & 4907 & 307.1 & 0.36 & 1.18 & 1.88 & 1.11 \\
\hline 1975 & 5054 & 259.5 & 0.42 & 1.24 & 1.92 & 1.25 \\
\hline 1980 & 5122 & 215.5 & 0.46 & 1.29 & 1.94 & 1.29 \\
\hline 1985 & 5111 & 191.7 & 0.56 & 1.21 & 1.84 & 1.27 \\
\hline 1990 & 5135 & 38.8 & 0.47 & 1.27 & 1.80 & 1.36 \\
\hline 1995 & 5216 & 5.5 & 0.30 & 2.60 & 3.71 & 3.34 \\
\hline 2000 & 5330 & 6.3 & 2.16 & 5.30 & 5.50 & 6.77 \\
\hline 2005 & 5411 & 7.9 & 2.57 & 3.22 & 10.61 & 7.40 \\
\hline 2010 & 5535 & 6.7 & 1.07 & 1.49 & 2.46 & 2.85 \\
\hline
\end{tabular}


during 1994-2007, 8\% (range 5-18\%) were known to be HIV positive ${ }^{12}$ (2006:19; 2007:17; 2008:21; 2009:22; 2010:36; 2011:34a).

In 2003, after a period with decreasing notification rates as compared to those of laboratory-confirmed cases, a reminder system based on laboratory reports to SSI was introduced. The reporting form and an explanatory letter concerning the duty to report were sent to the clinician attended by the patient. The result was a marked increase in numbers of notified cases ${ }^{12}$ (2004:50). Overall, data from the past two decades show a very low number of gonorrhoea cases.

\section{Laboratory surveillance system}

Age groups being used in the clinical notification system did not allow calculation of STD-relevant age-specific incidences why table 2 is based on data from the laboratory surveillance system. The male/female incidence ratios within the highly exposed age groups 15-19, 2024 and 25-29 years were constant during the period 1957-1990; subsequently, the total ratios were from three to seven times higher than previously recorded; the annual variation was pronounced, especially for the age group 25-29 years. The ratios for the age group 3034 years (data not shown) were similar to those for the 25-29 years age group. It should be noted that the numeric basis for the ratios changed dramatically over time, for example, in 1972, the incidences per 100000 for men and women aged 20-24 years were 1821 and 1468, respectively, and in 1996 they were 16 and 6.

Before the mid-1960s, the majority of female cases were identified by culture (table 1), whereas the majority of male cases notified were based on microscopy and not registered in the laboratory surveillance system. During 1965-1988, the numbers of notified and cultureconfirmed cases were approximately equal; however, the numbers of notified cases in men were consistently higher than those of culture-confirmed cases and vice versa in women. An attempt to estimate the numerical overlap between the two anonymous surveillance systems was made in 1981 on the basis of the gender, time and medical setting attended (data not shown). The analysis indicated an under-reporting at about 40\%. Until 1988, most cases (80-90\%) were diagnosed at the Neisseria Department. Following the abolition of The Venereal Disease Act in 1988 according to which diagnostic services had been available free of charge at SSI, such services were established at local DCMs. In 1996 and 2010, only $18 \%$ and $6 \%$ of confirmed cases were identified at SSI. During 2007-2010, the percentage of notified cases based on the culture of $N$. gonorrhoeae decreased from 94 to 75. Simultaneously, the percentage confirmed by NAATs increased from 0.6 to $17^{12}$ (2008:21; 2011:34a).

Table 1 shows selected examples of the annual surveys comprising gonorrhoea cases confirmed by culture of $N$. gonorrhoeae at SSI during 1957-1996. During the period from 1974 to 1988, the Venereal Disease Act of 1973 including the access to free diagnostic service was functional. It was characterised by a high testing activity and a high prevalence of gonorrhoea. Among 2038569 patients tested at the Neisseria Department, 141356 patients (78 213 men and 63143 women) with a cultureconfirmed diagnosis were identified.

Among factors crucial for the recovery rate of gonococci in clinical samples, the medium used for primary isolation and the clinical practice for sampling are important. Table 1 shows changes in antimicrobial supplements used over time; in particular, those including vancomycin have been recommended. ${ }^{7} 1314$ However, a priori, vancomycin was found to inhibit $3-5 \%$ of circulating gonococcal strains. ${ }^{7}$ To avoid selection and spread of the vancomycin-susceptible strains, all specimens received during 1974-1979 were inoculated onto two media, one with and one without antibiotic supplement. Owing to the high number of specimens that had to be handled in the early 1970 s, this laborious and expensive procedure needed simplification. Lincomycin at a concentration that did not inhibit any current strains replaced vancomycin in late $1979 .{ }^{14}$ To ensure that a selection of strains susceptible to lincomycin or other additives did not emerge and spread, duplicate inoculation onto selective as well as non-selective media was done during a 6-week period every second year from 1981 to 1991. No evidence of selection was found. The combined results for a total of 133710 specimens tested in duplicate were as follows: percentages of gonococcal isolates recovered on non-selective medium as compared to the selective medium in specimens from urethra: 84; cervix: 73; rectum: 28 and pharynx: $11 .^{15}$ During the past two decades, a pronounced variation in testing activity was evident, especially in men (figure 2). Another crucial factor for case finding in general and asymptomatic infections in particular is the clinical practice for sampling, that is, the importance of testing all possibly infected anatomical sites (complete sampling: urethra, (cervix), rectum and pharynx). As a marker for testing activity, the average numbers of specimens received per case identified were used (table 1). The highest testing activity was found during the period 1974-1988 with an average of 1.5-1.8 per male and 1.9-2.2 per female case identified. On the average, 36\% (range 30-42\%) of male and 25\% (range 19-30\%) of female patients with gonorrhoea were tested for pharyngeal gonorrhoea. During 1979, the composition of the selective medium and the laboratory procedure (inoculation onto one vs two media per specimen) were changed (table 1). It is noteworthy that the average of the recovery percentages then increased from $6 \%$ and $12 \%(1974-1978)$ to $12 \%$ and $19 \%$ (1980-1988) in men and women, respectively. Among patients with pharyngeal gonorrhoea, $40 \%$ of men and $30 \%$ of women had no concomitant urogenital gonorrhoea. During the period 1980-1988, 34\% (range $29-40 \%$ ) of men with gonorrhoea were tested for rectal infection; 9\% (range 3-13\%) were positive and the rectum was the only infected site in 67\% (range 52$77 \%)$. 
Figure 2 Prevalence of culture-confirmed pharyngeal and rectal gonorrhoea in men during 1973-2010.
Number

Percent

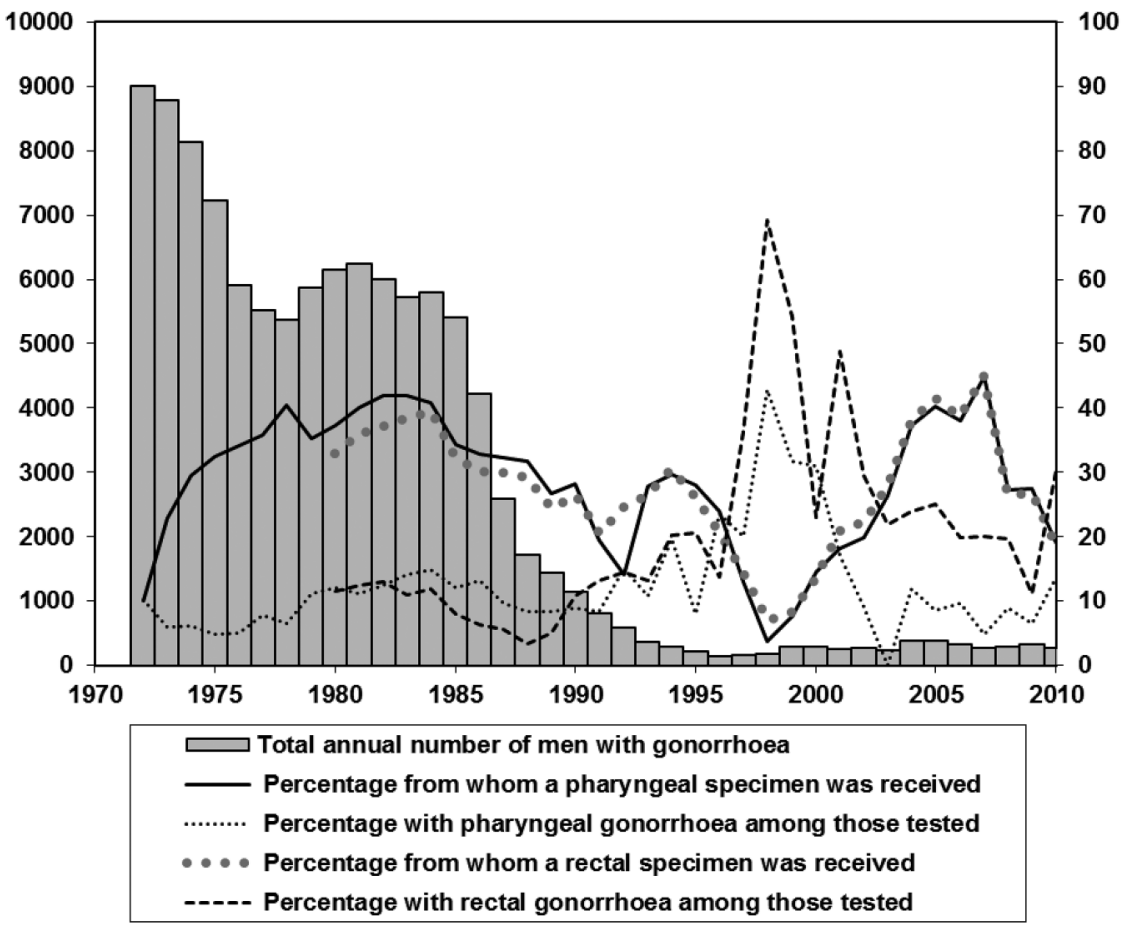

After the abolition of the Venereal Disease Act in 1988, local authorities closed the majority of STD clinics; hence, this clinical service was attended to by local general practitioners (GPs); simultaneously, a decrease in the average number of sampling sites was recorded.

During 1994-2010, the annual numbers of cases, especially in women, were low. To assess the impact of possible differences in current sampling practice of GPs and STD clinics, we pooled data for patients attending these two settings during the period 2003-2010. Complete sampling was reported for only $9 \%$ among 1873 patients with gonorrhoea (1523 men and 350 women) seen by GPs, but for $70 \%$ among 990 patients (853 men and 137 women) attending STD clinics. Thus, these findings confirm that differences in sampling

Table 3 Anatomical sites of infection in patients with gonorrhoea with complete sampling for culture of Neisseria gonorrhoeae, pooled data from 2003 to 2010

\begin{tabular}{|c|c|c|c|c|}
\hline & \multicolumn{2}{|l|}{ GPs } & \multicolumn{2}{|c|}{ STD clinics } \\
\hline & Men & Women & Men & Women \\
\hline $\begin{array}{l}\text { Number of patients with } \\
\text { gonorrhoea }\end{array}$ & 1523 & 350 & 853 & 137 \\
\hline \multicolumn{5}{|l|}{ Site of infection, \% } \\
\hline Urogenital & 89 & 100 & 88 & 91 \\
\hline Rectal & 15 & 22 & 15 & 22 \\
\hline Rectal only & 8 & 0 & 10 & 6 \\
\hline Pharyngeal & 8 & 7 & 7 & 11 \\
\hline Pharyngeal only & 2 & 0 & 2 & 3 \\
\hline
\end{tabular}

tradition still exist. However, among patients with complete sampling (table 3), the percentages of patients with urogenital, rectal, rectal only, pharyngeal or pharyngeal only gonorrhoea were similar for patients seen by GPs and for those attending STD clinics.

\section{DISCUSSION}

The clinical and the laboratory surveillance systems revealed the same changes in the gonorrhoea rate. As in other North-Western European countries, WW1 and WW2 as well as changes in social and economic conditions were associated with a high prevalence of syphilis and gonorrhoea. ${ }^{16}{ }^{17}$ No direct association between legislative approaches and changes in reported rates could be demonstrated (figure 1). Our data do illustrate the trends; nevertheless, both systems represent minimum figures since up to $40 \%$ under-reporting as well as under-diagnosing were noted periodically.

In Denmark, the very high prevalence of gonorrhoea in both genders in the beginning of the 1970s had a complex background. Factors which were used to explain the increase starting in 1965-1966 were not changed when the decrease started in 1973, namely the extended use of oral contraceptives (since 1965), changes in social family patterns with an increasing number of women working outside their homes, and an economy that allowed young people to travel abroad and to live on their own. Why did the observed incidence of gonorrhoea then decrease from 1972 to 1978 ? Around 1972, the following changes improving case finding were known to occur: the standard laboratory procedure for culture of gonococci was improved, 
especially increasing the recovery rates for pharyngeal and rectal specimens; simultaneously, asymptomatic pharyngeal gonorrhoea was recognised as a reservoir for which the standard treatment regimens were insufficient. ${ }^{10}$ It is thus possible that the high testing activity during the 1970s resulted in a reduction of the reservoir of patients with asymptomatic infections which partly may explain the decreasing gonorrhoea rate seen from 1972 onwards. Using NAATs as a diagnostic tool in the high-risk group patients, one recent study showed that isolated anorectal and oropharyngeal infections in patients with gonorrhoea accumulated to $76 \%$ of all infections in homosexual men and 59\% of all infections in female swingers and prostitutes, ${ }^{18}$ and another showed that $91 \%$ of rectal or pharyngeal infections in homosexual men would remain undetected if only symptomatic cases were tested. ${ }^{19}$

The performance characteristics and the heterogeneity of national STD surveillance systems in the European Union and Norway were analysed on the basis of a cross-sectional survey carried out in 2002-2003. The need for standardised case definitions and a minimum data set was underlined. ${ }^{20}$ In our study, the comparison of the performance of the surveillance systems was based on data from the high prevalence period 19741988 when the clinical notification system included a case definition, when testing and treatment were free of charge and when the laboratory service was centralised at a highly specialised unit at SSI (the WHO collaborating centre for reference and research in gonococci). On the basis of data from this period, we concluded that important factors for case finding-including patients with non-genital gonorrhoea-are clinical practice for specimen taking and the performance of diagnostic tests available. However, no information was available regarding complete or incomplete sampling of patients without culture-confirmed gonorrhoea.

Since the late 1970s, the concept of core groups has developed. $^{21}$ Traditionally, female prostitutes were considered the source of STDs and the core group for legislation and prevention strategies; most recently, the focus has been on homosexual men, ${ }^{22-24}$ especially due to their role in HIV transmission. ${ }^{25}$ The increasing male/ female age-specific incidence ratios (table 2) were consistent with the finding that in recent years, on the average, $45 \%$ of men had acquired the infection by homosexual contact.

Around 1984, the emerging AIDS epidemic motivated an official information campaign focusing on the promotion of safe sex. From this point, a marked decrease in the prevalence of male rectal gonorrhoea, in parallel with the overall decrease in the gonorrhoea rate, was seen. It is a matter of concern that during the same period, when the patients-or rather the homosexual male population-responded adequately to the information given, the medical profession responded in an inadequate way: the percentage of patients from whom a rectal specimen was taken fell markedly (figure 2). A similar pattern of changes was observed concerning the taking of pharyngeal specimens.

The result was a decrease in the percentage of patients in whom all possibly infected sites were examined. A comprehensive British study on sexual practice and attitudes recorded an expansion of heterosexual repertoires - particularly in oral and anal sex-over time (19902008) ${ }^{26}$ This finding underlines the importance of complete sampling in all patients on each occasion. Recently, it has been shown in patients at risk of STDs that universal testing is more sensitive in detecting anorectal infection than standard symptom-based and sexual history-based testing. ${ }^{27}$

The failure to demonstrate an influence of legal measures on the prevalence of gonorrhoea is in accordance with the following assessment in 1914 of the effect of 'The Act Regarding the Combating of Public Immorality and Venereal Infection' from $1906^{28}$ : "I regret to be obliged to state that these statistics, such as they are, and perhaps of limited value, at all events do not support the hopes of the promoters of the new sanitary system. The number of cases of syphilis and venereal disease in Denmark has not been reduced. The State regulation of prostitution has been a sanitary failure. The State regulation of venereal diseases by compulsory measures has been the same. I believe in extensive treatment, and still more in hygienic and preventive measures, which last may be the road of the future. The State has used till now the weapon of prohibition, but I believe the fight against these diseases must be left to the trained medical army, with the least possible assistance from the penal code and the police."

\section{CONCLUSIONS}

If homosexual men are considered the core group which maintains gonorrhoea at an endemic level in the general population, then the previous overall and continued decrease could be explained by the fact that the prevalence within the core group became so low that it continued to decrease outside the core group without any changes in behaviour of that group. The recent increase, especially in men, might be due to the insufficient sampling activity and other shortcomings of diagnostic procedures. ${ }^{29}{ }^{30} \mathrm{~A}$ further decrease in use of culture of $N$. gonorrhoeae is a matter for major concern as to the control of spread of antimicrobial resistance. ${ }^{31}$

Acknowledgements The authors acknowledge the skilled contribution of senior research technician Lene Berthelsen in collecting the data during the latest four decades of the study. They are indebted to the late BB Jørgensen, MD, Department of Treponematoses, SSI, for supplying data on the prevalence of early syphilis during 1900-1994, and to E Smith, MD, PhD, Department of Epidemiology, SSI, for supplying data on the prevalence of AIDS during 1980-1996.

Contributors IL conceived the article and wrote the first draft; established the laboratory surveillance system and was responsible for the organisation of the nationwide collection of data during 1957-1999; collated historical data from the clinical notification system since 1867 and researched on legislation and amendments of regulations governing control of sexually transmitted 
infections. SH was responsible for the laboratory surveillance system since 1999 and its adaptation to an increasing decentralisation of the laboratory diagnostic service; and produced the database and the graphs. Both IL and $\mathrm{SH}$ were involved in writing the final draft, as well as in analysis and interpretation of data, and take responsibility for the integrity of the data.

Competing interests None declared.

Funding This research received no specific grant from any funding agency in the public, commercial or not-for-profit sectors.

Provenance and peer review Not commissioned; externally peer reviewed.

Data sharing statement No additional data are available

Open Access This is an Open Access article distributed in accordance with the Creative Commons Attribution Non Commercial (CC BY-NC 4.0) license, which permits others to distribute, remix, adapt, build upon this work noncommercially, and license their derivative works on different terms, provided the original work is properly cited and the use is non-commercial. See: http:// creativecommons.org/licenses/by-nc/4.0/

\section{REFERENCES}

1. The National Health Service. The combating of venereal diseases in Denmark. Second Edition. Fr. Bagges Kgl. Hofbogtrykkeri. Copenhagen, Denmark, 1949.

2. National Board of Health. Guidelines for diagnosis and treatment of sexually transmitted diseases (in Danish). National Board of Health, Copenhagen, Denmark. 1989: ISBN 87-503-7757-4; 1992: ISBN 87-601-3394-5; 1999: ISBN 87-90765-39-7.

3. Jacobson W. Gram's discovery of his staining technique. J Infect 1983;7:97-101.

4. Lind I. Incidence of gonorrhoea in Denmark, 1957-1971. Br J Vener Dis 1973;49:454-9.

5. Reyn A. Laboratory diagnosis of gonococcal infections. Bull WId HIth Org 1965;32:449-69.

6. Reyn A. Recent developments in the laboratory diagnosis of gonococcal infections. Bull WId Hlth Org 1969;40:245-55.

7. Reyn A, Bentzon MW. Comparison of a selective and a non-selective medium in the diagnosis of gonorrhoea to ascertain the sensitivity of Neisseria gonorrhoeae to vancomycin. $\mathrm{Br} J$ Vener Dis 1972:48:363-8.

8. Reymann F. Cultivation of gonococci as diagnostic method in gonorrhoea in women. Acta Derm Venereol 1943;24:130-69.

9. Bang J. Demonstration of gonococci in rectal cultures. Acta Derm Venereol 1954;34:4-10.

10. Bro-Jørgensen A, Jensen T. Gonococcal pharyngeal infections. Report of 110 cases. Br J Vener Dis 1973;49:491-9.

11. Kvorning SA. Clinical comments on the start of an epidemic of syphilis. Br J Vener Dis 1963;39:261-3.

12. EPI-News-National Surveillance of Communicable Diseases, Statens Serum Institut, Copenhagen, Denmark 1982:39 (in Danish); 1987:13(in Danish); 1993:24 (in Danish); 2004:50; 2006:19; 2007:17; 2008:21; 2009:22; 2010:36; 2011:34a; 2011:35a; http:// www.ssi.dk/sw1204.asp

13. Thayer JD, Martin JE. A selective medium for the cultivation of N. gonorrhoeae and N. meningitides. Public Health Rep 1964;79:49-57.

14. Lind I. The laboratory diagnosis of gonorrhoea. International Congress Series no. 519: Recent Developments in laboratory identification techniques. Proceedings of the Symposium held at
Uppsala; 14-20 September 1979. Excerpta Medica, Amsterdam-Oxford-Princeton ISBN 9021994380.

15. Lind I. Gonorrhoea. In: Elsner P, Eichmann A. eds. Sexually transmitted disease. Advances in diagnosis and treatment. Current Problems in Dermatology. Vol 24. Basel: Karger, 1996:12-19.

16. Idsøe O, Guthe T. The rise and fall of the treponematoses I. Ecological aspects and international trends in venereal syphilis. $\mathrm{Br}$ $J$ Vener Dis 1967;43:227-43.

17. Catchpole MA. The role of epidemiology and surveillance systems in the control of sexually transmitted diseases. Genitourin Med 1996;72:321-9.

18. van Liere GA, Hoebe CJ, Dukers-Muijrers NH. Evaluation of the anatomical site distribution of chlamydia and gonorrhoea in men who have sex with men and in high-risk women by routine testing: cross-sectional study revealing missed opportunities for treatment strategies. Sex Transm Infect 2014;90:58-60.

19. Dudareva-Vizule S, Haar K, Sailer A, et al. Prevalence of pharyngeal and rectal Chlamydia trachomatis and Neisseria gonorrhoeae infections among men who have sex with men in Germany. Sex Transm Infect 2014;90:46-51.

20. Lowndes CM, Fenton KA. The ESSTI (European Surveillance of STIs) Network. Surveillance systems for STIs in the European Union: facing a changing epidemiology. Sex Transm Infect 2004:80:264-71.

21. Thomas JC, Tucker MJ. The development and use of the concept of a sexually transmitted disease core. J Infect Dis 1996;174(Suppl 2): S134-43.

22. Bignell C, Unemo M. 2012 European guideline on the diagnosis and treatment of gonorrhoea in adults. Int J STD AIDS 2013;24:85-92.

23. European Centre for Disease Prevention and Control. STI and HIV prevention in men who have sex with men in Europe. Stockholm: ECDC, 2013. ISBN: 978-92-9193-437-9.

24. Cohen J, Lo Y, Caceres CF, et al. WHO guideline working group. WHO guidelines for HIV/STI prevention and care among MSM and transgender people: implications for policy and practice. Sex Transm Infect 2013;89:536-8.

25. Galvin RG, Cohen MS. The role of sexually transmitted diseases in HIV transmission. Nat Rev Microbiol 2004;2:33-42.

26. Mercer HM, Tanton C, Prah P, et al. Changes in sexual attitudes and lifestyles in Britain through the life course and over time: findings from the National Surveys of Sexual Attitudes and Lifestyles (Natsal). Lancet 2013;382:1781-94.

27. van Liere GAFS, Hoebe CJPA, Niekamp A-M, et al. Standard symptom- and sexual history-based testing misses anorectal Chlamydia trachomatis and Neisseria gonorrhoeae infections in swingers and men who have sex with men. Sex Transm Dis 2013;40:285-9.

28. Pontoppidan E. Public measures against venereal disease in Denmark. BMJ 1914;2:282-3.

29. Smith DW, Tapsall JW, Lum G. Guidelines for the use and interpretation of nucleic acid detection test for Neisseria gonorrhoeae in Australia: a position paper on behalf of the Public Health Laboratory Network. Common Dis Intell Q Rep 2005;29:358-65.

30. Ison CA, Golparian D, Saunders P, et al. Evolution of Neisseria gonorrhoeae is a continuing challenge for molecular detection of gonorrhoea: false negative gonococcal porA mutants are spreading internationally. Sex Transm Infect 2013;89:197-201.

31. Ndowa F, Lusti-Narasimhan M, Unemo M. The serious threat of multidrug-resistant gonorrhoea: the pressing need for global action to control spread of antimicrobial resistance, and mitigate the impact on sexual and reproductive health. Sex Transm Infect 2012;88:317-18. 